\title{
The prevalence and clinical relevance of $2 R / 2 R$ TYMS genotype in patients with gastrointestinal malignancies treated with fluoropyrimidine-based chemotherapy regimens
}

\author{
Moh'd Khushman $\mathbb{D}^{1} \cdot$ Girijesh Kumar Patel $\mathbb{D}^{2,3} \cdot$ Anu Singh Maharjan ${ }^{4} \cdot$ Gwendolyn A. McMillin $^{4} \cdot$ Cindy Nelson ${ }^{1}$. \\ Peter Hosein ${ }^{5}$ - Ajay P. Singh ${ }^{6}$
}

Received: 1 July 2020 / Revised: 4 December 2020 / Accepted: 15 January 2021 / Published online: 19 February 2021

(c) The Author(s), under exclusive licence to Springer Nature Limited 2021. This article is published with open access

\begin{abstract}
Introduction The prevalence of $2 \mathrm{R} / 2 \mathrm{R}$ TYMS genotype is variable but estimated to be around $20-30 \%$ in Caucasians. The clinical relevance of TYMS $2 R / 2 R$ genotype in predicting severe fluoropyrimidine-related adverse events (FrAE) is controversial. Here, we explored the prevalence and clinical relevance of $2 R / 2 R$ TYMS genotype.

Methods Between 2011 and 2018, 126 patients were genotyped for TYMS. FrAEs were graded according to CTCAE version 5.0. Fisher's exact test was used for statistical analysis.

Results The prevalence of $T Y M S 2 R / 2 R$ genotype was $24.6 \%$. Among patients with TYMS genotypes $(N=71)$ that predict decreased TS expression, 2R/2R TYMS genotype was the most common TYMS genotype seen in female (57\%) and African American (60\%) patients. Among patients with genotypes that predict increased TS expression $(N=55), 12$ patients had grade 3-4 FrAEs (22\%), while among patients with genotypes that predict decreased TS expression $(N=71), 30$ patients had grade 3-4 FrAEs $(42 \%)(p=0.0219)$. Compared to patients with genotypes predicting increased TS expression, 17 out of 31 patients $(55 \%)$ with TYMS $2 R / 2 R$ genotype had grade 3-4 FrAEs $(p=0.0039)$ and 15 out 40 patients $(38 \%)$ with TYMS $2 R / 3 R C$ and TYMS $3 R C / 3 R C$ genotype had grade 3-4 FrAEs $(p=0.1108)$.

Conclusion The prevalence of TYMS $2 R / 2 R$ genotype was $24.6 \%$, and it had a unique sex and ethnic distribution. Polymorphism in the promoter region of TYMS gene that predicts decreased TS expression due to $2 R / 2 R$ variant was associated with grade 3-4 FrAEs. These data suggest that genotyping patients who are not DPD deficient for TYMS might identify patients at risk of severe FrAEs.
\end{abstract}

Moh'd Khushman

khushmanmd@gmail.com

1 Medical Oncology, Mitchell Cancer Institute, The University of South Alabama, Mobile, AL, USA

2 Department of Oncological Sciences, Mitchell Cancer Institute, The University of South Alabama, Mobile, AL, USA

3 Department of Cell Biology and Chemistry, Texas Tech University Health Sciences Center, Lubbock, TX, USA

4 ARUP Laboratories, The University of Utah, Salt Lake City, UT, USA

5 Hematology-Oncology, Sylvester Cancer Center, The University of Miami, Miami, FL, USA

6 Department of Pathology, The University of South Alabama, Mobile, AL, USA

\section{Introduction}

Fluoropyrimidines are antimetabolite chemotherapy drugs that are widely used in the treatment of cancer. There are three fluoropyrimidine drugs in clinical use: intravenous 5fluorouracil (5-FU), oral capecitabine, and oral tegafur. Capecitabine and tegafur are precursors of 5-FU [1, 2]. Fluoropyrimidines are considered the backbone of most chemotherapeutic regimens approved for the treatment of gastrointestinal (GI) malignancies [3]. They also represent treatment options in other malignancies such as breast and head and neck cancer $[4,5]$.

Among patients treated with 5-FU or capecitabine, approximately $20-25 \%$ of patients experience severe (grade 3-4) fluoropyrimidine-related adverse events (FrAEs) [6]. Severe FrAEs lead to patients' hospitalization and treatment interruption or discontinuation. The inter-individual variation 
in the occurrence and severity of FrAEs is partly due to genetic factors [7, 8].

Dihydropyrimidine dehydrogenase (DPD) enzyme, encoded by $D P Y D$ gene, is the rate-limiting enzyme for 5-FU catabolism, eliminating approximately $80 \%$ of administered or formed 5-FU [9]. Any variation in DPD activity can result in a cytotoxic accumulation of free 5-FU. The prevalence of DPD deficiency in Caucasians is approximately 3-5\% [10, 11]. African Americans, especially women, seem to have a higher prevalence of approximately $4-12 \%$ [12]. Genomic analysis of patients with DPD deficiency has identified over 128 mutations and polymorphisms in the $D P Y D$ gene, but only four high-risk variants $\left(D P Y D * 2 A, D P Y D^{*} 13, D P Y D^{*} 9 B\right.$, and HapB3) have been consistently associated with DPD deficiency and FrAEs. Genotyping for DPYD helps in identifying patients with DPD deficiency and guide the dosing of fluoropyrimidines. However, genotyping is limited to high-risk variants, and most patients who experience FrAEs are not DPD deficient [13-15].

In addition to DPYD, polymorphism in the TYMS gene that encodes thymidylate synthase (TS) may be associated with increased risk of FrAEs. TS is potently inhibited by 5-FU. Cells convert 5-FU to the metabolite fluorodeoxyuridine monophosphate, which binds to TS and inhibits the production of deoxythymidine monophosphate (dTMP). dTMP is essential for DNA replication and repair, so the lack of it leads to cell death [16, 17]. Fig. 1 shows the cascade of metabolic reactions where fluoropyrimidines inhibit TS and eventually lead to DNA damage.

TYMS gene expression is regulated by transcription factors that bind to the promoter region. The $5^{\prime}$ untranslated region contains a 28-base-pair variable number of tandem repeats (VNTRs), which act to enhance the promoter and transcriptional activity (Fig. 2). Most patients have either 2 $(2 \mathrm{R})$ or $3(3 \mathrm{R})$ repeats. Homozygous TYMS $3 R / 3 R$ genotype has a higher level of TS, while homozygous TYMS $2 R / 2 R$ genotype has low TS level and may be at greater risk of FrAEs $[18,19]$. A single-nucleotide polymorphism of the second repeat of the $3 \mathrm{R}$ allele (3RC) abolishes a binding site in the $3 \mathrm{R}$ second repeat allele and reduces TS activity compared to wild-type $3 R$ allele (3RG) [20].

The prevalence of $2 \mathrm{R} / 2 \mathrm{R}$ TYMS genotype in different ethnic background is variable but estimated to be around 20-30\% in Caucasians [21]. The clinical relevance of TYMS $2 R / 2 R$ genotype in predicting severe FrAEs is controversial [7, 19, 22-26]. Here, in a cohort of patients with GI malignancies treated with fluoropyrimidine-based chemotherapy regimens, we explored the prevalence and clinical relevance of $2 R / 2 R$ TYMS genotype. Moreover, given the different racial and sex background in our cohort, ethnic and sex differences were explored.

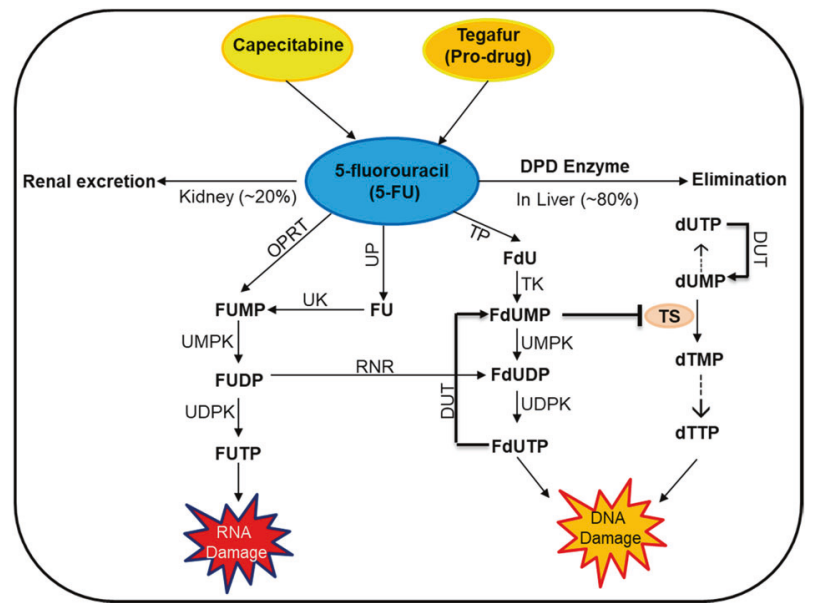

Fig. 1 Schematic representation of fluoropyrimidine-based drug metabolic pathway. The capecitabine and tegafur are the oral pre-pro and pro-drug, respectively, which in turn converted into 5-FU, while 5-FU is directly administered as IV. In normal condition of DPD and TS activity, maximum drug is eliminated from body while minimal amount is functionally active and inhibits the DNA and RNA synthesis leading to cell death during cancer treatment. Patients possessing the DPD deficiency show grade 3-4 toxicity as maximum drug is accumulated in the body that inhibit the TYMS. The TYMS $2 R / 2 R$ genotype has low TS level and correlated with severe fluoropyrimidines-related adverse events. DPD dihydropyrimidine dehydrogenase, UP uridine phosphorylase, UK uridine kinase, TK thymidine kinase, TP thymidine phosphorylase, TS thymidylate synthetase, OPRT orotate phosphoribosyltransferase, RNR ribonucleotide reductase, NME1-NME2 nucleoside diphosphate kinase.

\section{Materials and methods}

\section{Patient population}

This is a retrospective study conducted at the University of South Alabama Mitchell Cancer Institute in Mobile, Alabama, USA in collaboration with ARUP Laboratories, The University of Utah, Salt Lake City, Utah, USA. Cohort was identified through searching our cancer center tumor registry for patients with GI malignancies genotyped for TYMS gene between 2011 and 2018. The University of South Alabama Institutional Review Board (IRB) approved this study and the IRB-approved database provided a waiver of the requirement for informed consent and allowed for the publication of de-identified data.

\section{Fluoropyrimidine-based chemotherapy}

The fluoropyrimidine-based chemotherapy regimens that the patients in this cohort received include FOLFIRINOX, FOLFOX with or without bevacizumab, cetuximab or panitumumab, XELOX, FOLFIRI with or without bevacizumab, cetuximab or panitumumab, XELIRI with or without bevacizumab, cetuximab or panitumumab, FLOT, 5-FU and mitomycin, 5-FU and liposomal irinotecan, 


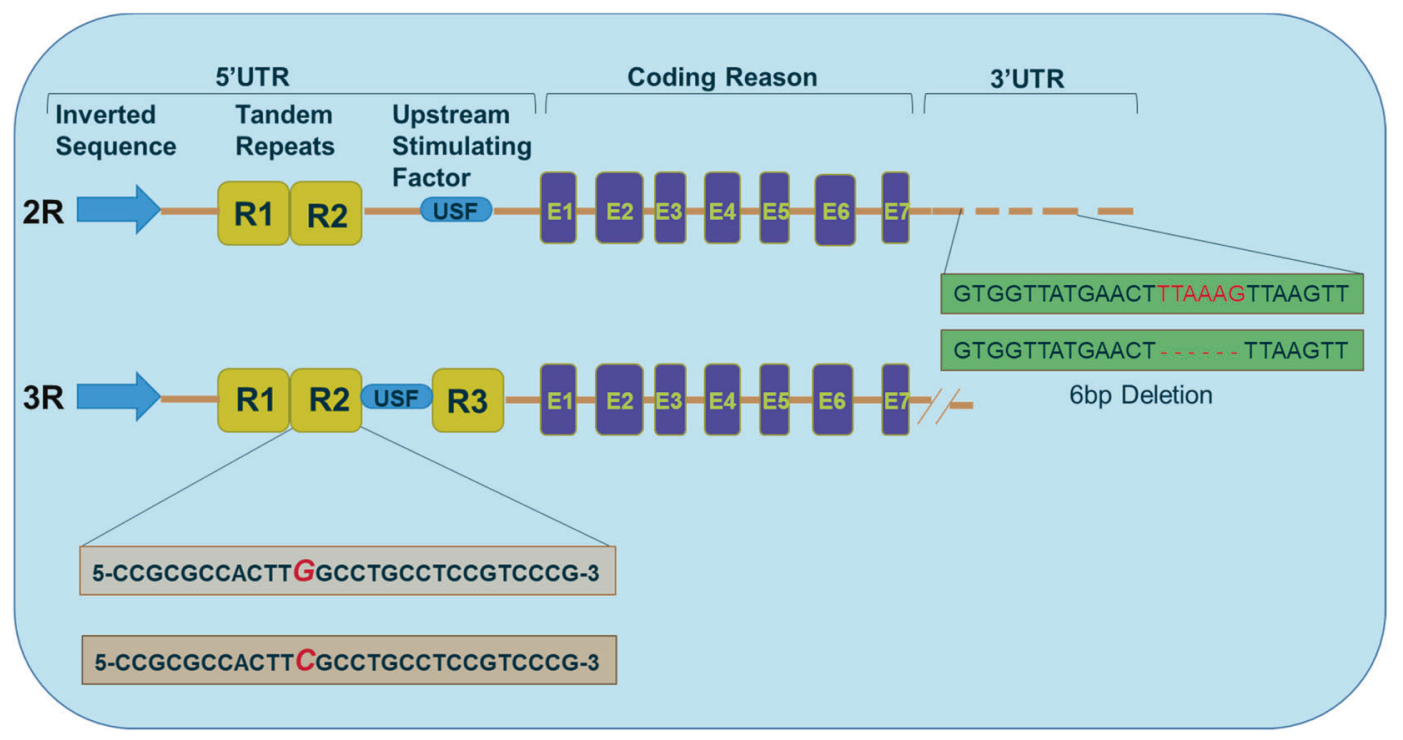

Fig. 2 Regulation of TYMS gene expression by $5^{\prime}$ and $3^{\prime}$ untranslated regions (UTRs). Upstream or $5^{\prime}$ UTR of the thymidylate synthase gene (TYMS) contains either two tandem repeats $(2 \mathrm{R})$ or three tandem repeats (3R) of 28-bp sequences. These tandem repeats regulate the transcription and translation of TYMS gene with the impaired enzyme activity. Moreover, other functional variants of the

capecitabine and gemcitabine, single agent 5-FU with or without concurrent radiotherapy, and capecitabine with or without concurrent radiotherapy. FOLFIRINOX consists of 5 -FU bolus of $400 \mathrm{mg} / \mathrm{m}^{2}$, 5-FU continuous infusion $2400 \mathrm{mg} / \mathrm{m}^{2}$ for $46 \mathrm{~h}$, leucovorin $400 \mathrm{mg} / \mathrm{m}^{2}$, oxaliplatin $85 \mathrm{mg} / \mathrm{m}^{2}$, and irinotecan $180 \mathrm{mg} / \mathrm{m}^{2}$ every 2 weeks. FOLFOX consists of 5 -FU bolus of $400 \mathrm{mg} / \mathrm{m}^{2}, 5$-FU continuous infusion $2400 \mathrm{mg} / \mathrm{m}^{2}$ for $46 \mathrm{~h}$, leucovorin $400 \mathrm{mg} / \mathrm{m}^{2}$, and oxaliplatin $85 \mathrm{mg} / \mathrm{m}^{2}$ every 2 weeks. XELOX consists of capecitabine $1000 \mathrm{mg} / \mathrm{m}^{2}$ twice daily for 2 weeks and oxaliplatin $130 \mathrm{mg} / \mathrm{m}^{2}$ every 3 weeks. FOLFIRI consists of 5 -FU bolus of $400 \mathrm{mg} / \mathrm{m}^{2}$, 5-FU continuous infusion $2400 \mathrm{mg} / \mathrm{m}^{2}$ for $46 \mathrm{~h}$, leucovorin $400 \mathrm{mg} / \mathrm{m}^{2}$, and irinotecan $180 \mathrm{mg} / \mathrm{m}^{2}$. XELIRI consists of capecitabine $1000 \mathrm{mg} / \mathrm{m}^{2}$ twice daily for 2 weeks and irinotecan $250 \mathrm{mg} / \mathrm{m}^{2}$ every 3 weeks. FLOT consists of 5-FU continuous infusion 2600 $\mathrm{mg} / \mathrm{m}^{2}$ for $24 \mathrm{~h}$, leucovorin $400 \mathrm{mg} / \mathrm{m}^{2}$, oxaliplatin $85 \mathrm{mg} / \mathrm{m}^{2}$, and docetaxel $50 \mathrm{mg} / \mathrm{m}^{2}$. 5-FU and mitomycin consist of 5FU $4000 \mathrm{mg} / \mathrm{m}^{2}$ and mitomycin $10 \mathrm{mg} / \mathrm{m}^{2}$. 5-FU and nanoliposomal irinotecan consists of 5-FU continuous infusion $2400 \mathrm{mg} / \mathrm{m}^{2}$ for $46 \mathrm{~h}$, leucovorin $400 \mathrm{mg} / \mathrm{m}^{2}$, and nanoliposomal irinotecan $70 \mathrm{mg} / \mathrm{m}^{2}$. Capecitabine and gemcitabine consist of capecitabine $1660 \mathrm{mg} / \mathrm{m}^{2}$ for 21 days and gemcitabine $1000 \mathrm{mg} / \mathrm{m}^{2}$ day 1,8 , and 15 every 4 weeks.

\section{Genotyping strategy}

Genotyping strategies were quite variable. The most common genotyping strategy was to genotype patients prior to initiating treatment with fluoropyrimidines-based
TYMS gene have been also identified such as single-nucleotide polymorphism (SNP) G>C within the second repeat of the $3 \mathrm{R}$ allele. Thymidylate synthase promoter $3 R C / 3 R C$ genotype causes lower transcriptional activity of TYMS, comparable with the TS $2 R / 2 R$ genotype. The six nucleotide insertion or deletion also identified to affect the RNA stability of TYMS gene.

chemotherapy. Between 2016 and 2018, genotyping was conducted almost universally on all patients with GI malignancies treated with fluoropyrimidines-based chemotherapy. Prior to 2016 , only 24 patients were genotyped and genotyping was conducted at the discretion of the treating medical oncologist. Those patients were genotyped either because they experienced toxicities or because they had significant comorbidities and their medical oncologist decided to do upfront genotyping.

\section{TYMS genotyping}

Germline DNA was obtained from peripheral blood specimens and genotyped TYMS gene in ARUP laboratories (Salt Lake City, UT, USA). The VNTRs of the 5'UTR flank of TYMS (rs45445694) and their additional single-nucleotide variant (SNV) $\mathrm{G}>\mathrm{C}$ in the first repeat of the $2 \mathrm{R}$ allele (rs183205964, named 2RG or 2RC), the SNV G>C in the second repeat of the $3 R$ allele (rs 2863542 , named $3 R G$ or $3 \mathrm{RC}$ ), and the $6 \mathrm{bp}$ insertion in the second repeat of the $3 \mathrm{R}$ allele (rs538469385) (all located into the rs45445694 variant) were performed by polymerase chain reactionrestriction fragment length polymorphism. A 6-bp deletion variant at the $3^{\prime} \mathrm{UTR}$ region of TYMS (rs151264360) was genotyped as well.

\section{DPYD genotyping}

Germline DNA was obtained from peripheral blood specimens and genotyped for high-risk $D P Y D$ variants $(I V S 14+1 G>A$ 
[DPYD*2A], DPYD c.1679T>G [DPYD*13A] and DPYD c.2846A $>$ T [DPYD*9B]) in ARUP laboratories (Salt Lake City, UT, USA). Only patients with no mutant high-risk $D P Y D$ variants were included in this cohort. Patients with mutant $D P Y D^{*} 9 A(c .85 T>C)$ were included in our cohort since the 2017 updated Clinical Pharmacogenetics Implementation Consortium guidelines for DPD genotype and fluoropyrimidine dosing and other studies stated that the $D P Y D * 9 A(c .85 T>C)$ does not affect DPD activity in a clinically relevant manner $[14,15]$.

\section{Toxicity grading and statistical analysis}

Demographic and clinical data were extracted from the patients' charts. FrAEs were graded according to the National Cancer Institute Common Terminology Criteria for Adverse Events (version 5.0). Association between dichotomous fluoropyrimidine-related toxicities and TYMS genotype was performed using Fisher's exact test. Analyses with $p$ values $\leq 0.05$ were considered significant. Tests were performed using GraphPad software QuickCalcs (GraphPad software 2016, San Diego, CA).

\section{Results}

\section{Patient characteristics}

Between 2011 and 2018, a total of 126 patients with GI malignancies were genotyped for TYMS and had no identifiable high-risk $D P Y D$ variants. The baseline characteristics of the patients are summarized in Table 1. Median age is 59 years. Males represented $55 \%$ of the patients, while females represented $45 \%$. In our cohort, $63 \%$ were Caucasian, 35\% were African Americans, and 2\% were other ethnicities (Hispanics, Asians, and Indian Americans). Colon adenocarcinoma represented the most common malignancy in our cohort. Other patients had anal squamous cell carcinoma, appendix adenocarcinoma, cholangiocarcinoma, esophageal adenocarcinoma, gastric adenocarcinoma, neuroendocrine tumor, pancreatic adenocarcinoma, and rectal adenocarcinoma. A fluorouracil-based chemotherapy regimen was administered in $74 \%$ of the patients, while $26 \%$ of the patients received a capecitabinebased chemotherapy regimen.

\section{TYMS genotyping}

TYMS genotypes that predict increased TS expression (3RG) $3 R G, 3 R G / 3 R C, 2 R / 3 R G, 2 R / 4 R, 3 R / 4 R, 4 R / 3 R G)$ were identified in 55 patients (44\%). TYMS genotypes that predict decreased TS expression $(2 R / 2 R, 2 R / 3 R C, 3 R C / 3 R C)$ were seen in 71 patients $(56 \%)$. In our cohort, patients with
Table 1 Patient baseline characteristics.

\begin{tabular}{lc}
\hline Patient characteristics & Number subject, $N[\%]$ \\
\hline Age (years) & $59(21-90)$ \\
$\quad$ Median (range) & \\
Sex & $57[45 \%]$ \\
Female & $69[55 \%]$ \\
Male & \\
Ethnicity & $44[35 \%]$ \\
African American & $3[2 \%]$ \\
Other ethnicities ${ }^{\mathrm{a}}$ & $79[63 \%]$ \\
Caucasians & \\
Diagnosis & $6[5 \%]$ \\
Anal SCC & $3[2 \%]$ \\
Appendix & $4[3 \%]$ \\
Cholangiocarcinoma & $50[40 \%]$ \\
Colon adenocarcinoma & $2[2 \%]$ \\
Esophageal adenocarcinoma & $8[6 \%]$ \\
Gastric adenocarcinoma & $3[3 \%]$ \\
Neuroendocrine tumor (SB) & $13[10 \%]$ \\
Pancreatic adenocarcinoma & $37[29 \%]$ \\
Rectal adenocarcinoma & \\
Chemotherapy regimen & $93[74 \%]$ \\
Fluorouracil-based & $33[26 \%]$ \\
Capecitabine-based & \\
\hline
\end{tabular}

$S C C$ squamous cell carcinoma, $S B$ small bowel.

${ }^{\mathrm{a}}$ Hispanics, Asians, and Indian Americans

$2 R / 2 R$ TYMS genotype represented $24.6 \%$ of the total cohort and $44 \%$ of the patients with genotypes that predict decreased expression of TS. TYMS genotyping in patients with genotypes that predict increased and decreased TS expression is summarized in Table 2.

\section{Sex differences}

In our cohort, the distribution of $2 R / 3 R G T Y M S$ genotype was similar between males and females. The distribution of all other genotypes apart from $2 R / 2 R$ and $3 R G / 3 R C T Y M S$ genotypes was more frequent in males than females. The $2 R / 2 R$ TYMS genotype had a very unique sex distribution where 20 out of 31 patients $(65 \%)$ were females. This is the only TYMS genotype where females were twice as common as males. In fact, among all the female patients in our cohort $(N=57)$, the $2 R / 2 R T Y M S$ genotype was present in 20 female patients $(35 \%)$. Moreover, among patients with TYMS genotypes that predict decreased TS expression, $2 R /$ $2 R$ TYMS genotype was the most common TYMS genotype seen in female patients $(57 \%)$. Of note, the three patients with $4 R$ containing $T Y M S$ genotypes $(2 R / 4 R, 3 R / 4 R$, and $4 R / 3 R G$ ) were all males. TYMS genotyping in patients with 
Table 2 TYMS genotyping in patients with GI malignancies with different racial and sex backgrounds.
Table 3 The frequency of grade 1-2 and grade 3-4 fluoropyrimidines-related adverse events in patients with TYMS genotypes that predict increased and decreased TS expression.

\begin{tabular}{|c|c|c|c|c|c|c|}
\hline \multirow{2}{*}{$\begin{array}{l}\text { TYMS genotyping } \\
(N=126)\end{array}$} & \multirow{2}{*}{$\begin{array}{l}\text { Number of } \\
\text { subjects } N[\%]\end{array}$} & \multicolumn{2}{|l|}{$\operatorname{Sex} N[\%]$} & \multicolumn{3}{|c|}{ Ethnicity $N[\%]$} \\
\hline & & Male & Female & Caucasians & AA & Others \\
\hline $\begin{array}{l}\text { Genotypes predictive of } \\
\text { increased TS expression }\end{array}$ & $55[44 \%]$ & $33[26.2 \%]$ & $22[17.5 \%]$ & $30[23.8 \%]$ & $23[18.3 \%]$ & $2[1.6 \%]$ \\
\hline $3 R G / 3 R G$ & 12 [9.5\%] & $11[8.7 \%]$ & $1[0.8 \%]$ & $6[4.8 \%]$ & $5[4.0 \%]$ & $1^{\mathrm{a}}[0.8 \%]$ \\
\hline $3 R G / 3 R C$ & $22[17.5 \%]$ & $10[7.9 \%]$ & $12[9.5 \%]$ & $19[15.1 \%]$ & $3[2.4 \%]$ & $0[0.0 \%]$ \\
\hline $2 \mathrm{R} / 3 \mathrm{RG}$ & 18 [14.3\%] & 9 [7.1\%] & $9[7.1 \%]$ & $5[4.0 \%]$ & $12[9.5 \%]$ & $1^{\mathrm{b}}[0.8 \%]$ \\
\hline $2 \mathrm{R} / 4 \mathrm{R}$ & $1[0.8 \%]$ & $1[0.8 \%]$ & $0[0.0 \%]$ & $0[0.0 \%]$ & $1[0.8 \%]$ & $0[0.0 \%]$ \\
\hline $3 \mathrm{R} / 4 \mathrm{R}$ & $1[0.8 \%]$ & $1[0.8 \%]$ & $0[0.0 \%]$ & $0[0.0 \%]$ & $1[0.8 \%]$ & $0[0.0 \%]$ \\
\hline $4 \mathrm{R} / 3 \mathrm{RG}$ & $1[0.8 \%]$ & $1[0.8 \%]$ & $0[0.0 \%]$ & $0[0.0 \%]$ & $1[0.8 \%]$ & $0[0.0 \%]$ \\
\hline $\begin{array}{l}\text { Genotypes predictive of } \\
\text { decreased TS } \\
\text { expression }\end{array}$ & $71[56 \%]$ & $36[28.6 \%]$ & $35[27.8 \%]$ & $50[39.7 \%]$ & $20[15.9 \%]$ & $1[0.8 \%]$ \\
\hline $2 \mathrm{R} / 2 \mathrm{R}$ & $31[24.6 \%]$ & $11[8.7 \%]$ & $20[15.9 \%]$ & $19[15.1 \%]$ & $12[9.5 \%]$ & $0[0.0 \%]$ \\
\hline $2 \mathrm{R} / 3 \mathrm{RC}$ & $31[24.6 \%]$ & $19[15.1 \%]$ & $12[9.5 \%]$ & $24[19.0 \%]$ & $7[5.6 \%]$ & $0[0.0 \%]$ \\
\hline $3 \mathrm{RC} / 3 \mathrm{RC}$ & $9[7.1 \%]$ & $6[4.8 \%]$ & $3[2.4 \%]$ & $7[5.6 \%]$ & $1[0.8 \%]$ & $1^{\mathrm{c}}[0.8 \%]$ \\
\hline
\end{tabular}

\begin{tabular}{|c|c|c|c|c|}
\hline \multirow[t]{2}{*}{ Adverse events } & \multicolumn{2}{|c|}{$\begin{array}{l}\text { TYMS genotypes that predict } \\
\text { increased TS expression }(N=55)\end{array}$} & \multicolumn{2}{|c|}{$\begin{array}{l}\text { TYMS genotypes that predict } \\
\text { decreased TS expression }(N=71)\end{array}$} \\
\hline & Grade $1-2$ & Grade $3-4$ & Grade $1-2$ & Grade $3-4$ \\
\hline Hematological & $N(\%)$ & $N(\%)$ & $N(\%)$ & $N(\%)$ \\
\hline Neutropenia & $16(29)$ & $3(5)$ & $21(30)$ & $4(6)$ \\
\hline Anemia & $10(18)$ & $0(0)$ & $16(23)$ & $0(0)$ \\
\hline Thrombocytopenia & $4(7)$ & $0(0)$ & $6(8)$ & $0(0)$ \\
\hline Neutropenic fever & & $0(0)$ & $0(0)$ & $0(0)$ \\
\hline Non-hematological & $N(\%)$ & $N(\%)$ & $N(\%)$ & $N(\%)$ \\
\hline Mucositis & $4(7)$ & $3(5)$ & $4(6)$ & $3(4)$ \\
\hline Nausea & $17(31)$ & $2(4)$ & $23(32)$ & $2(3)$ \\
\hline Vomiting & $3(5)$ & $2(4)$ & $5(7)$ & $1(1)$ \\
\hline Diarrhea & $4(7)$ & $9(16)$ & $7(13)$ & $11(15)$ \\
\hline Neurotoxicity & $3(5)$ & $0(0)$ & $3(4)$ & $4(6)$ \\
\hline Skin toxicity & $3(5)$ & $3(5)$ & $1(1)$ & $8(11)$ \\
\hline Fatigue & $30(55)$ & $2(4)$ & $27(38)$ & $5(7)$ \\
\hline Vasospasm & $0(0)$ & $1(2)$ & $0(0)$ & $4(6)$ \\
\hline
\end{tabular}

GI malignancies with different sex background is summarized in Table 2.

\section{Ethnic differences}

Caucasians were the majority in both genotypes that predict decreased TS expression and in genotypes (3RG/ $3 R G$ and $3 R G / 3 R C)$ that predict increased TS expression. Among patients with TYMS genotypes that predict decreased TS expression, $2 R / 2 R T Y M S$ genotype was the most common TYMS genotype seen in African American patients $(60 \%)$. Of note, the three patients with $4 R$ containing TYMS genotypes (2R/4R, 3R/4R, and 4R/3RG) were all African Americans. There was minimal representation of other ethnic backgrounds in our cohort. TYMS genotyping in patients with GI malignancies with mixed racial background is summarized in Table 2. 
Table 4 The frequency of grade 1-2 and grade 3-4 fluoropyrimidines-related adverse events in patients with TYMS genotypes that predict decreased TS expression $(2 R / 2 R$, $2 R / 3 R C$, and $3 R C / 3 R C$ genotypes).

\begin{tabular}{|c|c|c|c|c|c|c|}
\hline \multirow[t]{3}{*}{ Adverse events } & \multicolumn{6}{|c|}{ TYMS genotypes that predict decreased TS expression $(N=71)$} \\
\hline & \multicolumn{2}{|c|}{$2 \mathrm{R} / 2 \mathrm{R}(N=31)$} & \multicolumn{2}{|c|}{$2 \mathrm{R} / 3 \mathrm{RC}(N=31)$} & \multicolumn{2}{|c|}{$3 \mathrm{RC} / 3 \mathrm{RC}(N=9)$} \\
\hline & G $1-2$ & G 3-4 & G $1-2$ & G $3-4$ & G $1-2$ & G 3-4 \\
\hline Hematological & $N(\%)$ & $N(\%)$ & $N(\%)$ & $N(\%)$ & $N(\%)$ & $N(\%)$ \\
\hline Neutropenia & $11(35)$ & $1(3)$ & $9(29)$ & $1(3)$ & $1(11)$ & $2(22)$ \\
\hline Anemia & $8(26)$ & $0(0)$ & $6(19)$ & $0(0)$ & $2(22)$ & $0(0)$ \\
\hline Thrombocytopenia & $3(10)$ & $0(0)$ & $3(10)$ & $0(0)$ & $0(0)$ & $0(0)$ \\
\hline Neutropenic fever & $0(0)$ & $0(0)$ & $0(0)$ & $0(0)$ & $0(0)$ & $0(0)$ \\
\hline Non-hematological & $N(\%)$ & $N(\%)$ & $N(\%)$ & $N(\%)$ & $N(\%)$ & $N(\%)$ \\
\hline Mucositis & $2(6)$ & $3(10)$ & $1(3)$ & $0(0)$ & $1(11)$ & $0(0)$ \\
\hline Nausea & $13(42)$ & $2(6)$ & $9(29)$ & $0(0)$ & $1(11)$ & $0(0)$ \\
\hline Vomiting & $2(6)$ & $1(3)$ & $2(6)$ & $0(0)$ & $1(11)$ & $0(0)$ \\
\hline Diarrhea & $4(13)$ & $6(19)$ & $2(6)$ & $3(10)$ & $1(11)$ & $2(22)$ \\
\hline Neurotoxicity & $0(0)$ & $2(6)$ & $3(10)$ & $2(6)$ & $0(0)$ & $0(0)$ \\
\hline Skin toxicity & $1(3)$ & $3(10)$ & $0(0)$ & $4(13)$ & $0(0)$ & $1(11)$ \\
\hline Fatigue & $17(54)$ & $2(6)$ & $8(26)$ & $3(10)$ & $2(22)$ & $0(0)$ \\
\hline Vasospasm & $0(0)$ & $1(3)$ & $0(0)$ & $1(3)$ & $0(0)$ & $2(22)$ \\
\hline
\end{tabular}

Table 5 The association between grade 3-4 fluoropyrimidines-related adverse events (FrAEs) and TYMS genotypes.

\begin{tabular}{lll}
\hline Patients & Grade 3-4 FrAEs, $N[\%]$ & $p$ \\
\hline Patients with genotypes that predict increased TS expression $(N=55)$ & $12[22 \%]$ & $p=0.0219$ \\
Patients with genotypes that predict decreased TS expression $(N=71)$ & $30[42 \%]$ & $12[22 \%]$ \\
Patients with genotypes that predict increased TS expression $(N=55)$ & $17[55 \%]$ & $p=0.0039$ \\
Patients with $2 R / 2 R$ genotype that predict decreased TS expression $(N=31)$ & $12[22 \%]$ & $p=0.1108$ \\
Patients with genotypes that predict increased TS expression $(N=55)$ & $15[38 \%]$ &
\end{tabular}

Statistical analysis was performed using Fisher's exact test.

\section{Adverse events}

The frequency of grade 1-2 and grade 3-4 FrAEs in patients with TYMS genotypes that predict increased TS expression $(3 R G / 3 R G, 3 R G / 3 R C, 2 R / 3 R G, 2 R / 4 R, 3 R / 4 R$, $4 R / 3 R G)$ and $T Y M S$ genotypes that predict decreased TS expression $(2 R / 2 R, 2 R / 3 R C, 3 R C / 3 R C)$ is summarized in Table 3. None of the patients have died as a consequence of fluoropyrimidine-induced toxicities. The most commonly experienced adverse event in both group of patients with grade 3-4 FrAEs was diarrhea. Among patients with TYMS genotypes that predict decreased TS expression $(2 R / 2 R, 2 R /$ $3 R C, 3 R C / 3 R C$ ), the frequency of grade $1-2$ and grade $3-4$ FrAEs was further explored. Diarrhea was the most experienced grade 3-4 FrAE in patients with $2 R / 2 R$ TYMS genotype, while skin toxicity was the most experienced grade 3-4 FrAE in patients with TYMS $2 R / 3 R C$. Of note, grade 3-4 neutropenia and vasospasm were more experienced in patients with $T Y M S 3 R C / 3 R C$ compared to $2 R / 2 R$ and $2 R / 3 R C$ TYMS genotypes. The frequency of grade $1-2$ and grade 3-4 FrAEs in patients with TYMS genotypes that predict decreased TS expression $(2 R / 2 R, 2 R / 3 R C, 3 R C /$ $3 R C)$ is summarized in Table 4.

\section{Statistical analysis}

Among patients with TYMS genotypes that predict increased TS expression $(N=55), 12$ patients $(22 \%)$ had grade 3-4 FrAEs, while among patients with TYMS genotypes that predict decreased TS expression, 30 patients (42\%) had grade 3-4 FrAEs $(p=0.0219)$. Given the observed statistically significant difference, we explored the impact of the different TYMS genotypes that predict decreased TS expression $(2 R / 2 R, 2 R / 3 R C, 3 R C / 3 R C)$ on the observed results. Compared to patients with genotypes predicting increased TS expression, 17 out of 31 patients (55\%) with 2R/2R TYMS genotype had grade 3-4 FrAEs $(p=0.0039)$, while only 15 out 40 patients $(38 \%)$ with $2 R / 3 R C$ or $3 R C / 3 R C$ TYMS genotypes had grade 3-4 FrAEs $(p=0.1108)$. The association between grade 3-4 FrAEs and TYMS genotypes is shown in Table 5. Statistical analysis was performed using Fisher's exact test. 
Table 6 Summary of several studies that explored the prevalence of $2 \mathrm{R} / 2 \mathrm{R}$ TYMS genotype.

\begin{tabular}{|c|c|c|c|}
\hline Author & Population & $N$ & Prevalence $N(\%)$ \\
\hline Zhu & Case and control infants (American Caucasians) & 78 and 132 & $16(21)$ and $34(26)$ \\
\hline Zhu & Case and control infants (American Hispanics) & 144 and 396 & $25(17)$ and $70(18)$ \\
\hline De Jonge & $\begin{array}{l}\text { Children with ALL and matched control } \\
\text { (Netherlands) }\end{array}$ & 244 and 491 & $51(21)$ and $116(24)$ \\
\hline Gast & $\begin{array}{l}\text { Children with ALL and matched control } \\
\text { (Germany) }\end{array}$ & 457 and 541 & $95(21)$ and $111(21)$ \\
\hline Lightfoot & Children with ALL and matched control (UK) & 759 and 754 & $193(25)$ and $181(24)$ \\
\hline Petra & $\begin{array}{l}\text { Children with ALL and matched control } \\
\text { (Slovenia) }\end{array}$ & 68 and 252 & $17(25)$ and $76(30)$ \\
\hline Adleff & Colorectal (Hungary) & 102 & $18(17.6)$ \\
\hline Kristensen & Colorectal (Denmark) & 122 & $34(28)$ \\
\hline Vazquez & Healthy volunteers (Argentina) & 199 & $43(26.1)$ \\
\hline Canalle & Children with ALL and matched control (Brazil) & 126 and 300 & $33(26)$ and $53(18)$ \\
\hline Silva & Children with ALL and matched control (Brazil) & 140 and 390 & $25(18)$ and $66(17)$ \\
\hline Gallegos-Arreola & Colorectal and healthy subjects (Mexico) & 347 and 456 & $77(22)$ and $85(19)$ \\
\hline Chan & $\begin{array}{l}\text { Children with ALL and matched control } \\
\text { (Indonesia) }\end{array}$ & 184 and 177 & $30(16)$ and $0(0)$ \\
\hline Giovannetti & $\begin{array}{l}\text { Children with ALL and matched control } \\
\text { (Indonesia) }\end{array}$ & 71 and 44 & $1(1)$ and $0(0)$ \\
\hline Yeoh & $\begin{array}{l}\text { Children with ALL and matched control } \\
\text { (Singapore) }\end{array}$ & 518 and 652 & $12(2)$ and $15(2)$ \\
\hline Nazki & Children with ALL and matched control (India) & 43 and 144 & $8(19)$ and $14(10)$ \\
\hline
\end{tabular}

\section{Discussion}

The prevalence of $2 \mathrm{R} / 2 \mathrm{R}$ TYMS genotype in different ethnic background is quite variable. In Caucasian Americans, the prevalence of $2 \mathrm{R} / 2 \mathrm{R}$ TYMS genotype in infants with conotruncal heart defects and control group was $21 \%$ and $26 \%$, respectively. In the same study, the prevalence of $2 \mathrm{R} / 2 \mathrm{R}$ TYMS genotype in American Hispanics was 17\% and 18\%, respectively [27]. In children with acute lymphoblastic leukemia (ALL) and matched control, the prevalence of $2 \mathrm{R} / 2 \mathrm{R}$ TYMS genotype, respectively, was $21 \%$ and $24 \%$ in the Netherlands, $21 \%$ and $21 \%$ in Germany, $25 \%$ and $24 \%$ in United kingdom, and 25\% and 30\% in Slovenia [28-31]. In patients with colorectal cancer, the prevalence of $2 \mathrm{R} / 2 \mathrm{R}$ TYMS genotype was $18 \%$ in Hungary and $28 \%$ in Denmark [17, 32].

Many studies have explored the prevalence of $2 R / 2 R$ TYMS genotype in Hispanic population as well. In healthy volunteers from Argentina, the reported prevalence is $26 \%$ [33]. In Brazil, the prevalence of $2 \mathrm{R} / 2 \mathrm{R}$ TYMS genotype in children with ALL and matched control was $26 \%$ and $18 \%$, respectively, in one study and $21 \%$ and $24 \%$, respectively, in another study $[34,35]$. In Mexico, the prevalence of $2 \mathrm{R} /$ 2R TYMS genotype in patients with colorectal cancer and healthy subjects is $22 \%$ and $19 \%$, respectively.

The prevalence of $2 \mathrm{R} / 2 \mathrm{R}$ TYMS genotype in other ethnicities (Asians and Indians) showed lower reported prevalence compared to Caucasians and Hispanics. In children with ALL and matched control, the prevalence of $2 \mathrm{R} / 2 \mathrm{R}$
TYMS genotype, respectively, was $16 \%$ and $0 \%$ in one study and $1 \%$ and $0 \%$ in another study from Indonesia. The prevalence was $2 \%$ and $2 \%$ in Singapore and $19 \%$ and $10 \%$ in India [36-39]. Table 6 summarizes several studies that explored the prevalence of $2 \mathrm{R} / 2 \mathrm{R} T Y M S$ genotype.

In our cohort of 126 patients, the prevalence of $2 R / 2 R$ TYMS genotype was $24.6 \%$ of the total cohort and $44 \%$ of the patients with genotypes that predict decreased expression of TS. Among Caucasians $(N=80), 19$ patients $(24 \%)$ had $2 \mathrm{R} / 2 \mathrm{R}$ TYMS genotype, which is not very different from the reported prevalence of $2 \mathrm{R} / 2 \mathrm{R}$ TYMS genotype in Caucasians in America or Europe. Among African Americans $(N=43), 12$ patients (28\%) had 2R/2R TYMS genotype, which is slightly higher than the prevalence of $2 \mathrm{R} / 2 \mathrm{R}$ TYMS genotype in Caucasians. The prevalence of $2 \mathrm{R} / 2 \mathrm{R}$ TYMS genotype in African Americans is not well established. In one study that explored pharmacogenomics in patients with colorectal cancer, 36 patients were African Americans, and among this group, 25 patients (69\%) had either $2 R / 2 R$ or $2 R / 3 R$ TYMS genotypes [40].

Among male patients $(N=69), 11$ patients $(16 \%)$ had 2R/2R TYMS genotype. Among female patients $(N=57)$, 20 patients $(35 \%)$ had $2 \mathrm{R} / 2 \mathrm{R}$ TYMS genotype. It is important to emphasize that $60 \%$ (12 patients) of the female patients in our cohort with $2 \mathrm{R} / 2 \mathrm{R}$ TYMS genotype are African Americans. Several studies showed that women, especially African Americans, experienced more grade 3-4 fluoropyrimidine-associated toxicities compared to men. An 
underlying explanation is yet to be identified. The reported higher prevalence of $2 \mathrm{R} / 2 \mathrm{R}$ TYMS genotype in female African American patients in our study might represent one possible explanation. Certainly, this should be considered hypothesis-generating observation.

The role of $2 \mathrm{R} / 2 \mathrm{R}$ TYMS genotype in predicting severe FrAEs is controversial. The association between $2 R / 2 R$ TYMS genotype and FrAEs has been demonstrated in many but not all studies. In the positive studies, the sensitivity and positive predictive value were of limited clinical benefit. Among unselected 200 patients treated with 5-FU, grade 3-4 FrAEs were experienced in 44 patients $(22 \%)$. In this group of patients $(N=44), 13$ patients had $2 \mathrm{R} / 2 \mathrm{R}$ TYMS genotype (sensitivity $30 \%$ ). Among all the patients with $2 \mathrm{R} /$ 2R TYMS genotype $(N=25), 13$ patients experienced grade 3-4 FrAEs (positive predictive value 52\%) [7, 19, 22, 23].

On the other hand, several other studies failed to show a positive association between $2 \mathrm{R} / 2 \mathrm{R}$ TYMS genotype and FrAEs [23-26]. In one prospective study where TYMS genotyping was used to select the chemotherapy of choice in patients with rectal cancer, the rate of grade 3-4 FrAEs was less in patients with $2 R / 2 R, 2 R / 3 R$, or $2 R / 4 R T Y M S$ genotypes compared to patients with $3 R / 3 R$ or $3 R / 4 R$ TYMS genotypes (30\% vs $54 \%$ ). Moreover, the hospitalization rate was lower at $16 \%$ vs $34 \%$ [26].

Our patients with $2 \mathrm{R} / 2 \mathrm{R}$ TYMS genotype experienced different grade 3-4 hematological and non-hematological FrAEs. Diarrhea was the most common experienced grade 3-4 FrAEs. Other adverse events include neutropenia, mucositis, nausea, vomiting, neurotoxicity, skin toxicity, fatigue, and vasospasm. In our cohort, the association between 2R/2R TYMS genotype and FrAEs was noticeable. Compared to patients with genotypes predicting increased TS expression, $2 R / 2 R$ TYMS genotype was the only genotype among genotypes predicting decreased TS expression that had statistically significant association with grade 3-4 FrAEs $(p=0.0039)$. The association between the other genotypes $(2 R / 3 R C$ and $3 R C / 3 R C$ TYMS genotypes) and grade 3-4 FrAEs did not reach statistical significance $(p=0.1108)$.

Our study has several limitations. This study represents a single-institution experience with limited cohort of ethnic diversity. Our cohort was made of Caucasians and African Americans for the most part, and only three patients were from other ethnic backgrounds (Asian, Hispanic, and Indian American). Our cohort is also quite heterogenous regarding the primary site of the tumor and stage. It is also important to recognize that this study is a retrospective study and there are inherent limitations with a retrospective analysis, particularly regarding selection bias. TYMS genotyping strategies were quite variable as TYMS genotyping was at the discretion of the treating medical oncologist, and the selected treatment included several different fluoropyrimidine-based regimens. The medical oncologists followed the recommended dose management guidelines per package insert when they managed FrAEs. However, they still had a degree of variation in their practice. The process of attributing an experienced toxicity to 5-FU or capecitabine when they were part of fluoropyrimidine-based chemotherapy regimens was quite challenging sometimes. Every effort was made to make that attribution as accurate as possible. The aforementioned limitations should be kept in mind prior to drawing any conclusions.

\section{Conclusion}

The prevalence of TYMS $2 R / 2 R$ genotype in our cohort was 24.6\%. Among Caucasians and African Americans, it was $24 \%$ and $28 \%$, respectively. Polymorphism in the promoter region of TYMS gene that predict decreased TS expression due to $2 R / 2 R$ variant was associated with grade 3-4 FrAEs. These data suggest that genotyping patients who are not DPD deficient for TYMS might identify patients at risk of severe FrAEs.

The $2 R / 2 R$ TYMS genotype had a very unique sex and ethnic distribution. Among patients with TYMS genotypes that predict decreased TS expression $(2 R / 2 R, 2 R / 3 R C, 3 R C /$ $3 R C), 2 R / 2 R$ TYMS genotype was the most common TYMS genotype seen in female patients $(57 \%)$ and in African American patients $(60 \%)$. The reported higher prevalence of $2 R / 2 R$ TYMS genotype in female African American patients in our study might represent one possible explanation for why women, especially African Americans, experience more grade 3-4 FrAEs.

\section{Compliance with ethical standards}

Conflict of interest The authors declare that they have no conflict of interest.

Publisher's note Springer Nature remains neutral with regard to jurisdictional claims in published maps and institutional affiliations.

Open Access This article is licensed under a Creative Commons Attribution 4.0 International License, which permits use, sharing, adaptation, distribution and reproduction in any medium or format, as long as you give appropriate credit to the original author(s) and the source, provide a link to the Creative Commons license, and indicate if changes were made. The images or other third party material in this article are included in the article's Creative Commons license, unless indicated otherwise in a credit line to the material. If material is not included in the article's Creative Commons license and your intended use is not permitted by statutory regulation or exceeds the permitted use, you will need to obtain permission directly from the copyright holder. To view a copy of this license, visit http://creativecommons. org/licenses/by/4.0/. 


\section{References}

1. Hoff PM, Cassidy J, Schmoll HJ. The evolution of fluoropyrimidine therapy: from intravenous to oral. Oncologist. 2001;6:63-11.

2. Huang WY, Ho CL, Lee CC, Hsiao CW, Wu CC, Jao SW, et al. Oral tegafur-uracil as metronomic therapy following intravenous FOLFOX for stage III colon cancer. PLoS ONE 2017;12: e0174280.

3. Cassidy J, Saltz L, Twelves C, Van Cutsem E, Hoff P, Kang Y, et al. Efficacy of capecitabine versus 5-fluorouracil in colorectal and gastric cancers: a meta-analysis of individual data from 6171 patients. Ann Oncol. 2011;22:2604-9.

4. Ershler WB. Capecitabine monotherapy: safe and effective treatment for metastatic breast cancer. Oncologist. 2006;11:325-35.

5. Vermorken JB, Remenar E, van Herpen C, Gorlia T, Mesia R, Degardin M, et al. Cisplatin, fluorouracil, and docetaxel in unresectable head and neck cancer. N Engl J Med. 2007;357:1695-704.

6. Twelves C, Wong A, Nowacki MP, Abt M, Burris H, III, Carrato A. et al. Capecitabine as adjuvant treatment for stage III colon cancer. N Engl J Med. 2005;352:2696-704.

7. Lecomte T, Ferraz JM, Zinzindohoue F, Loriot MA, Tregouet DA, Landi B, et al. Thymidylate synthase gene polymorphism predicts toxicity in colorectal cancer patients receiving 5-fluorouracilbased chemotherapy. Clin Cancer Res. 2004;10:5880-8.

8. Khushman M, Patel GK, Hosein PJ, Laurini JA, Cameron D, Clarkson DR, et al. Germline pharmacogenomics of DPYD*9A (c.85T $>C$ ) variant in patients with gastrointestinal malignancies treated with fluoropyrimidines. J Gastrointest Oncol. 2018;9: 416-24.

9. Thorn CF, Marsh S, Carrillo MW, McLeod HL, Klein TE, Altman RB. PharmGKB summary: fluoropyrimidine pathways. Pharmacogenet Genomics. 2011;21:237-42.

10. Lu Z, Zhang R, Carpenter JT, Diasio RB. Decreased dihydropyrimidine dehydrogenase activity in a population of patients with breast cancer: implication for 5-fluorouracil-based chemotherapy. Clin Cancer Res. 1998;4:325-9.

11. Etienne MC, Milano G, Renee N, Lagrange JL, Dassonville O, Thyss A, et al. [Population study of dihydropyrimidine dehydrogenase in cancer patients]. Bull Cancer. 1995;82:705-10.

12. Mattison LK, Fourie J, Desmond RA, Modak A, Saif MW, Diasio $\mathrm{RB}$. Increased prevalence of dihydropyrimidine dehydrogenase deficiency in African-Americans compared with Caucasians. Clin Cancer Res. 2006;12:5491-5.

13. Offer SM, Fossum CC, Wegner NJ, Stuflesser AJ, Butterfield GL, Diasio RB. Comparative functional analysis of DPYD variants of potential clinical relevance to dihydropyrimidine dehydrogenase activity. Cancer Res. 2014;74:2545-54.

14. Amstutz U, Henricks LM, Offer SM, Barbarino J, Schellens JHM, Swen JJ, et al. Clinical Pharmacogenetics Implementation Consortium (CPIC) guideline for dihydropyrimidine dehydrogenase genotype and fluoropyrimidine dosing: 2017 update. Clin Pharm Ther. 2018;103:210-6.

15. Maharjan AS, McMillin GA, Patel GK, Awan S, Taylor WR, Pai $\mathrm{S}$, et al. The prevalence of DPYD*9A $(\mathrm{c} .85 \mathrm{~T}>\mathrm{C})$ genotype and the genotype-phenotype correlation in patients with gastrointestinal malignancies treated with fluoropyrimidines: updated analysis. Clin Colorectal Cancer. 2019;18:e280-6.

16. Parker WB, Cheng YC. Metabolism and mechanism of action of 5-fluorouracil. Pharm Ther. 1990;48:381-95.

17. Kristensen MH, Pedersen PL, Melsen GV, Ellehauge J, Mejer J. Variants in the dihydropyrimidine dehydrogenase, methylenetetrahydrofolate reductase and thymidylate synthase genes predict early toxicity of 5-fluorouracil in colorectal cancer patients. J Int Med Res. 2010;38:870-83.
18. Mandola MV, Stoehlmacher J, Muller-Weeks S, Cesarone G, Yu MC, Lenz HJ, et al. A novel single nucleotide polymorphism within the $5^{\prime}$ tandem repeat polymorphism of the thymidylate synthase gene abolishes USF-1 binding and alters transcriptional activity. Cancer Res. 2003;63:2898-904.

19. Pullarkat ST, Stoehlmacher J, Ghaderi V, Xiong YP, Ingles SA, Sherrod A, et al. Thymidylate synthase gene polymorphism determines response and toxicity of 5-FU chemotherapy. Pharmacogenomics J. 2001;1:65-70.

20. Thomas F, Hoskins JM, Dvorak A, Tan BR, McLeod HL. Detection of the G>C SNP and rare mutations in the 28-bp repeat of TYMS using gel-based capillary electrophoresis. Pharmacogenomics. 2010;11:1751-6.

21. Gallegos-Arreola MP, Zuniga-Gonzalez GM, Sanchez-Lopez JY, Cruz AYN, Peralta-Leal V, Figuera LE, et al. TYMS 2R3R polymorphism and DPYD [IVS]14+1G $>$ A gene mutation in Mexican colorectal cancer patients. Acta Biochim Pol. 2018;65:227-34.

22. Ichikawa W, Takahashi T, Suto K, Sasaki Y, Hirayama R. Orotate phosphoribosyltransferase gene polymorphism predicts toxicity in patients treated with bolus 5-fluorouracil regimen. Clin Cancer Res. 2006;12:3928-34.

23. Rosmarin D, Palles C, Church D, Domingo E, Jones A, Johnstone E, et al. Genetic markers of toxicity from capecitabine and other fluorouracil-based regimens: investigation in the QUASAR2 study, systematic review, and meta-analysis. J Clin Oncol. 2014;32:1031-9.

24. Loganayagam A, Arenas Hernandez M, Corrigan A, Fairbanks L, Lewis CM, Harper $\mathrm{P}$, et al. Pharmacogenetic variants in the DPYD, TYMS, CDA and MTHFR genes are clinically significant predictors of fluoropyrimidine toxicity. $\mathrm{Br} \mathrm{J}$ Cancer. 2013;108:2505-15.

25. Sharma R, Hoskins JM, Rivory LP, Zucknick M, London R, Liddle $\mathrm{C}$, et al. Thymidylate synthase and methylenetetrahydrofolate reductase gene polymorphisms and toxicity to capecitabine in advanced colorectal cancer patients. Clin Cancer Res. 2008; $14: 817-25$.

26. Tan BR, Thomas F, Myerson RJ, Zehnbauer B, Trinkaus K, Malyapa RS, et al. Thymidylate synthase genotype-directed neoadjuvant chemoradiation for patients with rectal adenocarcinoma. J Clin Oncol. 2011;29:875-83.

27. Zhu H, Yang W, Shaw N, Perloff S, Carmichael SL, Finnell RH, et al. Thymidylate synthase polymorphisms and risk of conotruncal heart defects. Am J Med Genet. A 2012;158A:2194-203.

28. de Jonge R, Tissing WJ, Hooijberg JH, Jansen G, Kaspers GJ, Lindemans $\mathrm{J}$, et al. Polymorphisms in folate-related genes and risk of pediatric acute lymphoblastic leukemia. Blood. 2009;113: 2284-9.

29. Gast A, Bermejo JL, Flohr T, Stanulla M, Burwinkel B, Schrappe $\mathrm{M}$, et al. Folate metabolic gene polymorphisms and childhood acute lymphoblastic leukemia: a case-control study. Leukemia. 2007;21:320-5.

30. Lightfoot TJ, Johnston WT, Painter D, Simpson J, Roman E, Skibola CF, et al. Genetic variation in the folate metabolic pathway and risk of childhood leukemia. Blood. 2010;115:3923-9.

31. Petra BG, Janez J, Vita D. Gene-gene interactions in the folate metabolic pathway influence the risk for acute lymphoblastic leukemia in children. Leuk Lymphoma. 2007;48:786-92.

32. Adleff V, Hitre E, Koves I, Orosz Z, Hajnal A, Kralovanszky J. Heterozygote deficiency in thymidylate synthase enhancer region polymorphism genotype distribution in Hungarian colorectal cancer patients. Int J Cancer. 2004;108:852-6.

33. Vazquez C, Orlova M, Scibona P, Diaz Arce H, Pallotta MG, Belloso WH. Prevalence of thymidylate synthase gene $5^{\prime}$ untranslated region variants in an Argentinean sample. Genet Mol Res. 2017;16. 
34. Canalle R, Silveira VS, Scrideli CA, Queiroz RG, Lopes LF, Tone LG. Impact of thymidylate synthase promoter and DNA repair gene polymorphisms on susceptibility to childhood acute lymphoblastic leukemia. Leuk Lymphoma 2011;52:1118-26.

35. Silva RM, Fontes AC, Silva KA, Sant'Ana TA, Ramos FJ, Marques-Salles Tde J, et al. Polymorphisms involved in folate metabolism pathways and the risk of the development of childhood acute leukemia. Genet Test Mol Biomark. 2013;17: 147-52.

36. Chan JY, Ugrasena DG, Lum DW, Lu Y, Yeoh AE. Xenobiotic and folate pathway gene polymorphisms and risk of childhood acute lymphoblastic leukaemia in Javanese children. Hematol Oncol. 2011;29:116-23.

37. Giovannetti E, Ugrasena DG, Supriyadi E, Vroling L, Azzarello A, de Lange $\mathrm{D}$, et al. Methylenetetrahydrofolate reductase
(MTHFR) C677T and thymidylate synthase promoter (TSER) polymorphisms in Indonesian children with and without leukemia. Leuk Res. 2008;32:19-24.

38. Yeoh AE, Lu Y, Chan JY, Chan YH, Ariffin H, Kham SK, et al. Genetic susceptibility to childhood acute lymphoblastic leukemia shows protection in Malay boys: results from the MalaysiaSingapore ALL Study Group. Leuk Res. 2010;34:276-83.

39. Nazki FH, Masood A, Banday MA, Bhat A, Ganai BA. Thymidylate synthase enhancer region polymorphism not related to susceptibility to acute lymphoblastic leukemia in the Kashmir population. Genet Mol Res. 2012;11:906-17.

40. Sanoff HK, Sargent DJ, Green EM, McLeod HL, Goldberg RM. Racial differences in advanced colorectal cancer outcomes and pharmacogenetics: a subgroup analysis of a large randomized clinical trial. J Clin Oncol. 2009;27:4109-15. 